\title{
Política de recursos humanos para a reforma gerencial: realizações do período 1995-2002 1
}

\section{RSP}

Revista do

Serviço

Público

Ano 53

Número 4

Out-Dez 2002

\author{
Regina Silvia Pacheco
}

“Ao contrário do propalado 'desmantelamento do Estado', as reformas fortaleceram a administração federal e valorizaram seus servidores segundo critérios de desempenho e qualificação. Diante da extraordinária expansão dos principais programas federais nesse período, a conclusão é inevitável: o governo consegue fazer muito mais com menos servidores, porém mais qualificados."

\section{Presidente Fernando Henrique Cardoso ${ }^{2}$}

Este texto pretende apresentar a evolução recente dos efetivos na função pública brasileira, com ênfase na esfera federal. Busca relacionar tal evolução com a agenda de reforma do aparelho de Estado, em implantação no país desde janeiro de 1995, data de início do primeiro mandato do Governo Fernando Henrique Cardoso. Em especial, discute a evolução dos efetivos face à política de recursos humanos e aos imperativos de ajuste fiscal. Se o controle dos efetivos, desde 1995, era um imperativo decorrente da necessidade de controle das despesas com pessoal, teve também por objetivo alterar o perfil da força de trabalho na Administração Pública Federal, em direção a um perfil mais condizente com os novos papéis do Estado na esfera federal.

Desde os anos 80, a prestação direta de serviços ao cidadão vem sendo descentralizada da União para os Estados e municípios; com a Constituição de 1988, aprofundou-se esta descentralização. A partir do início dos anos 90, o governo brasileiro implementou um amplo programa de privatização de suas empresas estatais, premido pela crise financeira, que impedia o setor público de realizar os investimentos necessários. Por meio deste programa, as empresas de telefonia, siderurgia, petroquímica, ferrovias e parte

Regina Silvia

Pacheco é

presidente da

ENAP Escola

Nacional de

Administração

pública, desde

março

de 1995.

Professora

doutora da

EAESP-FGV -

São Paulo,

licenciada.

Contato: regina.pacheco@ enap.gov.br 
do setor elétrico e das rodovias, além de bancos estaduais, foram transferidos para a iniciativa privada; ao mesmo tempo, o Governo Federal criou novas agências para regular e fiscalizar os setores privatizados. ${ }^{3}$

Este movimento, que ocorreu em vários países, levando a uma profunda revisão dos papéis do Estado central, assumiu, no Brasil, a partir de 1995, o desafio de fortalecer o núcleo estratégico do Estado responsável pela formulação de políticas públicas nacionais e pelas novas funções de regulação. Assim, o principal objetivo da reforma do Estado, impulsionada a partir de 1995, não era o Estado mínimo, mas o Estado forte em seus novos papéis:

"A reforma do Estado deve ser entendida dentro do contexto da redefinição do papel do Estado, que deixa de ser o responsável direto pelo desenvolvimento econômico e social pela via da produção de bens e serviços, para fortalecer-se na função de promotor e regulador desse desenvolvimento. Busca-se o fortalecimento das funções de regulação e de coordenação do Estado, particularmente no nível federal, e a progressiva descentralização vertical, para os níveis estadual e municipal, das funções executivas no campo da prestação de serviços sociais e infra-estrutura. Pretende-se reforçar a governança - a capacidade de governo do Estado — através da transição programada de um tipo de administração pública burocrática, rígida e ineficiente, voltada para si própria e para o controle interno, para uma administração pública gerencial, flexível e eficiente, voltada para o atendimento do cidadão". ${ }^{4}$

O Presidente Fernando Henrique, em seu balanço de sete anos de governo, afirma: “O objetivo não é o Estado-mínimo nem máximo, mas o Estado necessário". 5

Especificamente para o núcleo estratégico do Estado, o Plano Diretor propôs:

- "Aumentar a efetividade do núcleo estratégico, de forma que os objetivos democraticamente acordados sejam adequada e efetivamente alcançados"; e

- "Modernizar a administração burocrática, através de uma política de profissionalização do serviço público, ou seja, de uma política de carreiras, de concursos públicos anuais, de programas de educação continuada permanente, de uma efetiva administração salarial, ao mesmo tempo em que se introduz no sistema burocrático uma cultura gerencial baseada na avaliação de desempenho". ${ }^{6}$ 
A fim de obter tais resultados, foi imprescindível atuar sobre o perfil da força de trabalho da administração federal. A ênfase nas novas funções do Estado exigia um quadro enxuto e altamente qualificado de funcionários, movidos pelo compromisso com resultados, e não apenas pelo cumprimento de formalidades legais ou obediente e acomodado com a perspectiva de estabilidade e aposentadoria integral. Sabia-se que a agenda de reforma seria longa - tanto em função da rigidez constitucional, que vedava a demissão de servidores e garantia a estabilidade plena, quanto por se tratar de uma profunda mudança cultural.

Em 1995, dois terços dos cargos na Administração Pública Federal eram de nível médio; menos de $40 \%$ dos servidores tinham escolaridade de nível superior. ${ }^{7}$ Quaisquer que sejam as explicações e heranças históricas para tal fenômeno, a constatação é bastante evidente: não era um perfil da força de trabalho adequado para enfrentar os desafios do governo central. Com o aprofundamento da reforma do Estado, onde ao Governo Federal cabe cada vez menos a prestação direta de serviços à população ou a produção de mercadorias, e cada vez mais as atividades de formulação e avaliação de políticas públicas, regulação e fomento, delineou-se um imperativo para a política de recursos humanos, a partir de 1995: alterar profundamente o perfil da força de trabalho, em direção a um quadro mais qualificado de servidores. A Tabela 1 mostra a evolução dos cargos e da escolaridade dos servidores federais a partir de 1995.

Tabela 1: Evolução do nível de escolaridade superior dos cargos e dos servidores

\begin{tabular}{l|c|c|c|c|c|c|c|c} 
(em \%) & 1999 & 1996 & 1997 & 1998 & 1999 & 2000 & 2001 & $2002 /$ ago \\
\hline $\begin{array}{l}\text { Nível de } \\
\text { escolaridade } \\
\text { superior }\end{array}$ & 1995 & & & & & & & \\
\hline Do cargo & n.d. & 33,5 & 34,3 & 34,6 & 36,4 & 37,0 & 38,9 & 39,7 \\
\hline Do servidor & 34,8 & n.d. & 43,9 & 46,0 & 48,6 & 49,3 & 52,6 & 53,6 \\
\hline
\end{tabular}

Fonte: MP — Boletim Estatístico de Pessoal, vários números.

A Tabela 1 mostra que, apesar da rigidez constitucional, a força de trabalho da Administração Pública Federal tem evoluído dentro da diretriz traçada: tanto os cargos de nível superior como os servidores com escolaridade universitária têm aumentado, tendo evoluído, respectivamente, em mais de 5 e mais de 16 pontos percentuais, entre 1995 e 2001. Em 2001, pela primeira vez, os servidores de nível superior passaram a constituir mais da metade da força de trabalho do Governo Federal.

Ainda que a informação possa ter alguma distorção, dadas possíveis imprecisões ou desatualizações do cadastro ${ }^{8}$, os dados indicam 
uma verdadeira revolução no perfil da força de trabalho no setor público federal — da qual ainda não se deram conta formadores de opinião ou pesquisadores.

Outro imperativo decorreu da necessidade de manter sob controle a evolução de gastos com pessoal. Com o plano de estabilização econômica adotado desde 1994, o Plano Real, o governo assumiu o compromisso de promover o ajuste fiscal, passando a adotar, a partir de 1998, com o Programa de Estabilização Fiscal, metas anuais de superávit primário, em torno de 3\% do Produto Interno Bruto. Mas o programa de governo abrangia ainda a retomada de investimentos em projetos de infra-estrutura e a expansão do gasto social; assim, os gastos com pessoal, responsáveis em 1995 por $56,2 \%$ da receita corrente líquida da União, deveriam ter sua expansão controlada. A Tabela 2 mostra a evolução dos gastos com pessoal:

\section{Tabela 2: Relação entre despesas com pessoal e receita corrente líquida da União}

(em R \$ milhões correntes)

\begin{tabular}{|c|c|c|c|c|c|}
\hline \multirow[t]{2}{*}{ Ano } & \multicolumn{2}{|c|}{$\begin{array}{l}\text { Despesa de pessoal } \\
\text { (1) }\end{array}$} & \multicolumn{2}{|c|}{$\begin{array}{l}\text { Receita corrente } \\
\text { líquida }(\mathrm{RCL})(2)\end{array}$} & \multirow{2}{*}{$\begin{array}{l}\text { \% da despesa } \\
\text { pessoal sobre } \\
\text { RCL }\end{array}$} \\
\hline & $\mathrm{R} \$$ & base & $\mathrm{R} \$$ & base & \\
\hline 1995 & $37.825,5$ & 100 & $67.298,1$ & 100 & 56,2 \\
\hline 1996 & $40.900,9$ & 108,1 & $89.352,7$ & 132,8 & 45,8 \\
\hline 1997 & $44.529,7$ & 117,7 & $97.040,6$ & 144,2 & 45,9 \\
\hline 1998 & $47.944,8$ & 126,8 & $104.491,4$ & 155,3 & 45,9 \\
\hline 1999 & $51.571,0$ & 136,3 & $129.854,4$ & 193,0 & 39,7 \\
\hline 2000 & $56.093,3$ & 148,3 & $148.201,5$ & 220,2 & 37,8 \\
\hline 2001 & $59.212,2$ & 156,5 & $148.201,5$ & 220,2 & 35,3 \\
\hline
\end{tabular}

Fonte: MP — Boletim Estatístico de Pessoal no 77, agosto/2002.

(1) Inclui ativos e aposentados da administração direta (executivo civil e militar, legislativo e judiciário) e indireta (autarquias, fundações, empresas públicas e sociedades de economia mista).

(2) $\mathrm{RCL}=$ receita corrente da União menos transferências constitucionais e legais para Estados e municípios, benefícios previdenciários e contribuição para o PIS/PASEP.

De acordo com a Tabela 2, nota-se que a diminuição da porcentagem dos gastos com pessoal sobre a receita corrente líquida da União, a partir de 1995, deu-se em grande parte graças ao expressivo aumento da arrecadação. Esta é também a visão de Luiz Carlos Bresser Pereira: ao afirmar que a reforma administrativa tinha um duplo objetivo — transitar da administração burocrática para a administração gerencial, e contribuir para o ajuste fiscal, Bresser Pereira considera que o primeiro objetivo obteve mais êxito do que o segundo: 
"Sempre disse que a reforma tinha dois objetivos. O principal era o de tornar o aparelho do Estado e a administração pública brasileira mais modernos, transitar de uma administração pública burocrática para uma gerencial, ou, como Pedro Parente preferiu, para uma gestão empreendedora. Este objetivo foi alcançado no plano das reformas institucionais e principalmente no plano da mudança de cultura. Hoje a cultura burocrática está em franca retirada, enquanto uma nova cultura gerencial ou empreendedora, que concede mais autonomia e mais responsabilidade aos gestores públicos, está em alta. A reforma administrativa, entretanto, afinal não foi ainda bem sucedida em relação a seu segundo objetivo — contribuir para o ajuste fiscal — porque a indefinição de quais sejam as carreiras de Estado impede que se demitam, por excesso de despesas, servidores. Este problema não existe a nível federal, mas é importante no plano estadual e municipal. Os êxitos alcançados pelo governo federal na área fiscal devem-se a outras razões que não a própria reforma administrativa, como, por exemplo, a lei de responsabilidade fiscal". (Bresser Pereira: fevereiro/2002, www.bresserpereira.org.br) ${ }^{9}$

Alguns analistas ou veículos de imprensa criticam o Governo Federal por não ter avançado na demissão de servidores — por excesso de despesa ou por insuficiência de desempenho. ${ }^{10}$ No entanto, tais análises deixam de considerar o importante aspecto acima discutido: o da mudança do perfil da força de trabalho da Administração Pública Federal.

Aliando os dois imperativos - alterar o perfil da força de trabalho e manter sob controle as despesas com pessoal, o Governo Federal vem praticando uma política de recursos humanos que abrange as seguintes ações: aumentos diferenciados para carreiras do núcleo estratégico do Estado, revisão da legislação para correção de distorções e eliminação de privilégios, concursos anuais de ingresso para determinadas carreiras, reorganização das carreiras de Estado. Três programas de demissão incentivada foram anunciados, mas sem adesão expressiva dos servidores. ${ }^{11}$

\section{Evolução dos quantitativos e participação no mercado de trabalho}

O número de servidores civis ativos do Poder Executivo Federal vem decrescendo desde 1989'12: passou de 712.740 para 460.470 (setembro/ 2001), com uma redução de 35\%. Já nos Poderes Legislativo e Judiciário há aumento de quantitativos desde 1995. 
Tabela 3: Evolução do quantitativo de servidores civis ativos*

\begin{tabular}{l|c|c|l|l}
\hline Ano & Executivo & Executivo + estatais & Legislativo & Judiciário \\
\hline 1988 & 705.548 & & & \\
\hline 1989 & 712.740 & 1.488 .608 & & \\
\hline 1990 & 628.305 & 1.312 .682 & & \\
\hline 1991 & 598.375 & 1.238 .817 & & \\
\hline 1992 & 620.870 & 1.261 .037 & & \\
\hline 1993 & 592.898 & 1.236 .538 & & \\
\hline 1994 & 583.020 & 1.216 .058 & & \\
\hline 1995 & 567.689 & 1.140 .711 & 17.402 & 64.561 \\
\hline 1996 & 554.736 & 1.068 .063 & 17.623 & 69.646 \\
\hline 1997 & 531.725 & 994.805 & 19.155 & 74.504 \\
\hline 1998 & 513.720 & 919.732 & 18.787 & 76.207 \\
\hline 1999 & 497.125 & 871.918 & 21.343 & 79.677 \\
\hline 2000 & 486.912 & 809.585 & 19.458 & 80.932 \\
\hline 2001 & 458.743 & 776.736 & 19.889 & 80.899 \\
\hline
\end{tabular}

Fonte: MP — Boletim Estatístico de Pessoal no 77, agosto/2002.

* Inclui contrato temporário.

A evolução foi similar nos governos estaduais e inversa nos municípios, onde houve aumento do número de servidores. Os dados são apresentados nas Tabelas 4 e 5:

Tabela 4: Nível de emprego no mercado de trabalho formal por setor (empregados entre 18 e 65 anos)

\begin{tabular}{l|c|c|c|c|c|c}
\hline Setor & \multicolumn{2}{|c|}{1993} & \multicolumn{2}{c|}{1996} & \multicolumn{2}{c}{1999} \\
\hline & n.a. & base & n.a. & base & n.a. & base \\
\hline Privado & 18.613 .498 & 100 & 20.227 .471 & 109 & 21.173 .920 & 114 \\
\hline Público & 6.930 .173 & 100 & 6.925 .067 & 100 & 6.853 .368 & 99 \\
\hline Federal & 1.392 .746 & 100 & 1.373 .130 & 99 & 1.224 .993 & 88 \\
\hline Estadual & 3.245 .108 & 100 & 3.102 .412 & 96 & 2.898 .286 & 89 \\
\hline Municipal & 2.292 .319 & 100 & 2.449 .525 & 107 & 2.730 .089 & 119 \\
\hline Total & 25.543 .671 & 100 & 27.152 .538 & 106 & 28.027 .288 & 110 \\
\hline
\end{tabular}

Fonte: Marconi, 2001. 
Tabela 5: Participação no total de empregados (entre 18 e 65 anos) no mercado de trabalho formal por setor (em \%)

\begin{tabular}{l|r|r|c}
\hline Setor & 1993 & 1996 & 1999 \\
\hline Privado & 72,9 & 74,5 & 75,5 \\
\hline Público & 27,1 & 25,5 & 24,5 \\
\hline Federal & 5,5 & 5,1 & 4,4 \\
\hline Estadual & 12,7 & 11,4 & 10,3 \\
\hline Municipal & 9,0 & 9,0 & 9,7 \\
\hline Total & 100 & 100 & 100 \\
\hline
\end{tabular}

Fonte: Marconi, 2001.

Entre 1993 e 1999, o número de empregos públicos federais e estaduais diminui 12 e 11 pontos percentuais, respectivamente, enquanto que os empregos municipais crescem 19\%. A participação do emprego público no total de empregos formais cai 2,6 pontos percentuais, tendo apenas os empregos municipais aumentado em 0,9 pontos percentuais sua participação no total de empregos.

Segundo dados do Ministério do Trabalho, citados em estudo recente do Banco Nacional do Desenvolvimento Econômico e Social (BNDES), estima-se que, em 2000, havia 6,1 milhões de servidores públicos em todo o país. Este total representava $23,2 \%$ dos 26,2 milhões de empregos formais em todo o país. Considerando-se o universo de trabalhadores ocupados no país, abrangendo mercado formal e informal de trabalho, segundo estimativas do BNDES para 2000, a participação do emprego no setor público cai para $10 \%{ }^{13}$ Não há dados sobre a categoria dos "terceirizados", considerada empregada do setor privado, mas paga pelo setor público são os funcionários de empresas que prestam serviços terceirizados para estatais e governos.

A participação do emprego público no mercado formal de trabalho tem variação de quase quatro vezes entre os 26 Estados e Distrito Federal: enquanto que em Santa Catarina o emprego público representa apenas 15,8\% dos empregos formais, ou 17,1\% em São Paulo, nos Estados menores o poder público ainda é importante empregador e gerador de renda: no Acre, 58,5\% do emprego formal vem da administração pública; no Distrito Federal, 50,3\%; em 13 Estados, a participação do setor público é superior a $1 / 3$ do total de empregos formais. ${ }^{14}$ Isto talvez explique a dificuldade de o Congresso aprovar medidas que alterem as condições de trabalho no setor público, no contexto do federalismo brasileiro; apenas como exemplo, pode-se lembrar que a alteração das leis trabalhistas (que regulam o mercado formal de trabalho no setor privado) teve tramitação rápida e foi 
aprovada pelo Congresso no final de 2000, enquanto que a regulamentação de vários dispositivos da Emenda Constitucional no 19, de maio de 1998, relativa à administração pública, enfrenta forte resistência dos parlamentares.

\section{Política de remuneração}

O Governo Federal alterou profundamente a política de remuneração que vinha sendo praticada desde a Constituição de 1988. Enquanto que a tradição sempre foi a de corrigir os salários linearmente (mesmo índice de reajuste para todos os servidores), a partir de 1995 o governo passou a praticar aumentos diferenciados, buscando corrigir distorções entre o setor público e o setor privado.

Tradicionalmente, os salários do setor público sempre foram mais elevados que os do setor privado para os cargos de menor qualificação, e inferiores nos cargos mais qualificados. Em 1995, ano da elaboração do Plano Diretor da Reforma do Aparelho do Estado, a comparação das remunerações médias era a seguinte:

Tabela 6: Salários médios - setor privado e setor público (em R\$ de maio/1995)

\begin{tabular}{l|c|c|c}
\hline Nível dos cargos & $\begin{array}{c}\text { Salário médio } \\
\text { setor privado }\end{array}$ & $\begin{array}{c}\text { Salário médio } \\
\text { setor público }\end{array}$ & $\begin{array}{c}\text { Diferença } \\
\text { público/privado }\end{array}$ \\
\hline Cargos executivos & 7.080 & 6.069 & $-14 \%$ \\
\hline Cargos de nível superior & 1.899 & 1.814 & $-5 \%$ \\
\hline Cargos de nível médio & 926 & 899 & $-3 \%$ \\
\hline Cargos operacionais & 437 & 635 & $+45 \%$ \\
\hline
\end{tabular}

Fonte: MARE, 1995 — Plano Diretor da Reforma do Aparelho do Estado.

O governo Fernando Henrique havia ainda herdado um expressivo aumento linear de salários concedido ao final do governo anterior. ${ }^{15}$ A partir de 1995, sem perder de vista os imperativos do ajuste fiscal, o governo buscou elevar o padrão de remuneração do setor público, tendo como parâmetro o setor privado. Passou a praticar uma política de reajustes diferenciados, tendo revisado substancialmente a remuneração de cerca de 40 carreiras estruturadas: "diversas categorias do serviço público, sobretudo em áreas essenciais da atividade do Estado, tiveram seus salários revistos com base nas remunerações pagas no setor privado, gerando reajustes que chegaram em alguns casos a mais de $200 \%$."16

Buscou também aumentar a "amplitude" de algumas carreiras, entendida como a diferença entre a remuneração inicial e final em cada carreira. Tal amplitude vinha sendo sistematicamente reduzida, chegando 
a descaracterizar o significado de "carreira", por meio de um expediente corporativo que tratava de pressionar para cima a remuneração inicial da carreira. Foram reestruturadas 14 carreiras e 43 cargos, beneficiando 43.643 servidores. ${ }^{17}$

Cerca de 233 mil servidores federais não pertencem a carreiras estruturadas, integrando o Plano Geral de Classificação de Cargos (PCC). ${ }^{18}$ Para estes servidores, foram criadas duas gratificações, a serem atribuídas segundo critérios de complexidade dos postos de trabalho, desempenho individual e resultados institucionais alcançados. Também nestes dois instrumentos o objetivo é valorizar o desempenho e a qualificação dos servidores, e recompensar os de melhor desempenho:

- em 2000, foram criadas 8.703 Funções Comissionadas Técnicas $(\mathrm{FCT})^{19}$, possibilitando que o desempenho técnico especializado seja avaliado e recompensado, tendo por inspiração a "carreira em Y" adotada por empresas privadas; pelo projeto original, o número de FCTs deverá chegar a $50 \mathrm{mil}$; e

- no início de 2002, foi criada a GDATA ${ }^{20}$, a ser atribuída com base no desempenho individual do servidor e institucional do seu órgão de lotação.

Tal política salarial praticada pelo governo Fernando Henrique foi sistematicamente rejeitada pelos sindicatos da base do funcionalismo, e incompreendida pelos meios de comunicação — que tenderam a repetir que "o Governo Federal deixou o funcionalismo sete anos sem reajuste de salários". Trata-se na verdade de uma nova política remuneratória, condizente com as diretrizes de alteração da força de trabalho na esfera federal, e compatível com as restrições impostas pelo ajuste fiscal. Por meio dos reajustes diferenciados, o Governo Federal buscou reter seus quadros mais qualificados, e atrair novos servidores para as carreiras de Estado - para as quais foram organizados concursos anuais de ingresso.

De toda forma, o salário médio real ainda é maior no setor público, e maior na esfera federal. É em nível municipal, no entanto, que o salário médio real mais aumentou - sendo também o que apresenta o mais baixo ponto de partida (ver as tabelas seguintes).

Tabela 7: Evolução da massa salarial por setor (para os empregados entre 18 e 65 anos; $1993=100$ )

\begin{tabular}{l|l|l|l}
\hline & 1993 & 1996 & 1999 \\
\hline Privado & 100 & 133 & 131 \\
\hline Público & 100 & 125 & 123 \\
\hline Federal & 100 & 107 & 100 \\
\hline Estadual & 100 & 126 & 119 \\
\hline Municipal & 100 & 163 & 185 \\
\hline Total & 100 & 130 & 128 \\
\hline
\end{tabular}

Fonte: Marconi, 2001. 
Tabela 8: Evolução do salário médio real (valores em R\$ de setembro/99; deflator INPC)

\begin{tabular}{l|r|r|r}
\hline & 1993 & 1996 & 1999 \\
\hline Privado & 454 & 562 & 527 \\
\hline Público & 816 & 1.001 & 990 \\
\hline Federal & 1.440 & 1.512 & 1.598 \\
\hline Estadual & 783 & 1.029 & 1.038 \\
\hline Municipal & 395 & 607 & 598 \\
\hline
\end{tabular}

Fonte: Marconi, 2001.

Tabela 9: Remuneração média mensal dos trabalhadores formais -2000 (em salários mínimos)

\begin{tabular}{l|c}
\hline Esfera & Remuneração média (SM) \\
\hline Federal & 13,0 \\
\hline Estadual & 6,8 \\
\hline Municipal & 3,9 \\
\hline Empresas públicas & 14,0 \\
\hline Média - Setor Público & $\mathbf{6 , 9}$ \\
\hline Média - Total da pop. ocupada & $\mathbf{3 , 9}$ \\
\hline
\end{tabular}

Fonte: RAIS 2000 — segundo BNDES-AFE (2002).

Uma outra distorção, de difícil correção, refere-se aos importantes desníveis de remuneração entre os três poderes: a remuneração nos Poderes Legislativo e Judiciário é bastante superior à do Executivo, drenando muitas vezes boa parte dos quadros qualificados para aqueles dois poderes. Até a Emenda Constitucional de 1998, os Poderes Legislativo e Judiciário tinham plena autonomia para fixar seus próprios salários; com a emenda, estes poderes passam a ter que fazê-lo por meio de projeto de lei encaminhado ao Congresso, sujeito à sanção presidencial. Tais diferenças têm ainda impedido regulamentar o dispositivo da emenda constitucional de 1998 que define um teto único para remuneração no setor público, que deve abranger os três poderes; as propostas do Executivo, de um teto de R \$ 8 mil ou de R \$ 10,8 mil, têm sido rejeitadas pelo Judiciário.

Os dados, a seguir, evidenciam as distorções salariais entre os três poderes: 
Tabela 10: Evolução da remuneração média dos servidores da União por poder — servidores ativos

(em $\mathrm{R} \$$ - valores reais, base dezembro/97)

\begin{tabular}{l|l|l|l|l|l}
\hline Poder & 1995 & 1996 & 1997 & 1998 & 1999 \\
\hline Executivo (1) & 2.031 & 1.925 & 1.944 & 1.764 & 2.233 \\
\hline Legislativo & 4.855 & 4.967 & 5.161 & 5.111 & 5.131 \\
\hline Judiciário & 3.390 & 3.029 & 3.479 & 4.384 & 4.023 \\
\hline
\end{tabular}

Fonte: MP — Boletim Estatístico de Pessoal no 56, dezembro/2000.

(1) Servidores civis ativos; estão excluídos militares, empregados de empresas públicas e de sociedades de economia mista.

Tabela 11: Remuneração média dos servidores da União por poder (em $\mathbf{R} \$$ de novembro/2000)

\begin{tabular}{l|c|c|c|l}
\hline $\begin{array}{l}\text { Poder ou } \\
\text { situação } \\
\text { funcional }\end{array}$ & Ativos & Aposentados & $\begin{array}{l}\text { Instituidores } \\
\text { de pensão }\end{array}$ & $\begin{array}{l}\text { Média } \\
\text { total }\end{array}$ \\
\hline Executivo & 2.490 & 1.878 & 1.541 & 2.095 \\
\hline Empresas públicas & 3.065 & - & - & 3.065 \\
\hline Soc.Econ.Mista & 3.000 & - & - & 3.000 \\
\hline Militares & 1.274 & 2.507 & 1.532 & 1.601 \\
\hline Legislativo & 5.117 & 4.869 & 2.398 & 4.647 \\
\hline Judiciário & 5.122 & 6.108 & 3.454 & 5.188 \\
\hline
\end{tabular}

Fonte: MP — Boletim Estatístico de Pessoal número 56, dezembro/2000.

A margem de ação do Executivo federal para controlar as despesas com pessoal tem sido cada vez menor. Por um lado, qualquer tentativa de discussão a respeito das distorções salariais entre os poderes tende a ser vista como uma ingerência do Executivo, ferindo a autonomia dos poderes. Por outro lado, cresce a massa de servidores aposentados, cuja despesa é incomprimível. Desde o ano de 1998, no Executivo federal, o número de servidores aposentados e instituidores de pensão já ultrapassa o número de servidores ativos; em agosto de 2002, havia 459.821 servidores civis ativos, contra 601.586 servidores civis aposentados e instituidores de pensão (ou $56,7 \%$ do total). Dadas as peculiaridades do regime de aposentadoria no setor público, no Brasil, as despesas com aposentados públicos tende a ser um problema crescente. 


\section{$O$ regime de aposentadoria no setor público}

O Brasil é um dos poucos países do mundo (ao lado da Espanha) onde a aposentadoria no setor público é garantida com remuneração integral. Até antes da reforma gerencial, iniciada em 1995, o servidor recebia mesmo um aumento de remuneração de até $20 \%$ ao passar para a aposentadoria.

O ritmo das aposentadorias tende a aumentar a cada vez que o sistema é questionado. Segundo o Plano Diretor da Reforma do Estado, entre o início de 1991 e junho de 1995, houve 110 mil novas aposentadorias; só em 1991, talvez por efeito do governo Collor, mais de 46 mil servidores se aposentaram. O ritmo retomou expressão entre 1995 e 1998 (nos quatro anos, 106.213 aposentadorias foram concedidas), em parte por receio dos servidores de que o sistema de aposentadoria no setor público fosse reformado. A partir de 1999, o ritmo caiu, registrando 8,7 mil aposentadorias naquele ano e cerca de 6 mil nos dois anos seguintes.

A idade média de passagem à aposentadoria é bastante baixa para padrões internacionais: os servidores se aposentam em média com 55 anos de idade (e os professores, com idade ainda mais baixa). Até 1998, a aposentadoria no setor público dependia apenas de comprovação de tempo de serviço - para aposentadoria integral, 35 anos de serviço para homens e 30 para mulheres (podendo-se somar, sem restrições, os tempos de serviço nos setores público e privado). Com a emenda constitucional no 20 , de dezembro de 1998, passou a ser exigida idade mínima para aposentadoria: 60 anos para homens e 55 anos para mulheres ${ }^{21}$, e ainda um mínimo de 10 anos de trabalho no setor público. Mas a regra só valerá plenamente para os servidores que ingressaram no setor público a partir de dezembro de 1998; para os que ingressaram antes desta data, foi fixada uma regra de transição.

Além de explosivo do ponto de vista fiscal, o sistema é ainda injusto do ponto de vista social, se comparado ao regime geral da previdência para o conjunto dos trabalhadores do setor privado. Neste, há um teto para os benefícios da aposentadoria, que é de 10 salários de referência (inferior ao salário mínimo); a média das aposentadorias do setor privado é de 1,7 salário mínimo, sendo que $73 \%$ dos aposentados recebem um salário mínimo e $90 \%$ até cinco salários mínimos. No setor público, o servidor aposenta-se com vencimentos integrais, sem limite, e o valor médio das aposentadorias é de 15 salários mínimos no Executivo, 36 salários mínimos no Legislativo e de 38 salários mínimos no Poder Judiciário. 22

Por outro lado, a Constituição garante que todos os reajustes dados aos servidores ativos devem ser repassados aos inativos. E a despesa recai sobre o conjunto dos contribuintes: o sistema é financiado em cerca de $85 \%$ pelo Tesouro. No sistema geral de previdência do setor privado, 
para cada $\mathrm{R} \$ 1$ arrecadado de contribuição do trabalhador é gasto cerca de $\mathrm{R} \$ 1,9$; no setor público, a despesa se eleva a $\mathrm{R} \$ 4,6$ para cada real arrecadado.

Em vista de tantos privilégios e desequilíbrios, o Plano Diretor da Reforma já afirmava, em 1995: “a reforma do sistema previdenciário do servidor público é um passo fundamental e imprescindível para o equacionamento da crise fiscal e a própria reforma do Estado".

No entanto, pouco se avançou na reforma das aposentadorias do setor público. O governo buscou aumentar o patamar de contribuição dos servidores, criando alíquotas progressivas; a ação foi suspensa pelo Supremo Tribunal Federal, e acabou sendo revogada por lei, a partir de iniciativa encaminhada pelo Executivo, para evitar novas ações judiciais. Busca aprovação para criar um regime de aposentadoria pública baseado em um sistema de contribuição definida, sem que o Congresso conclua a votação do projeto (PLC 9/1999). O Congresso aprovou lei instituindo a contribuição de inativos, mas sua aplicação foi suspensa pelo Supremo Tribunal Federal.

\section{Estabilidade rígida}

Consagrada na Constituição de 1988, a estabilidade rígida dos servidores públicos foi estendida a cerca de 500 mil funcionários, que haviam sido contratados para fundações e autarquias, sem qualquer concurso público, pelo regime geral da Consolidação das Leis Trabalhistas (CLT). A legislação complementar — o Regime Jurídico Único do Servidor Público - previa apenas a demissão em caso de falta grave, devendo a falta ser apurada por comissão de pares. Na realidade, este tipo de demissão é quase impraticável, e nos poucos casos em que é efetivada, a justiça tende a dar ganho de causa ao servidor exonerado, fazendo com que ele seja reintegrado ao trabalho ${ }^{23}$, ou o processo é tornado nulo.

A reforma gerencial entendeu que a estabilidade deveria ser flexibilizada: o servidor passaria a ser passível de demissão não apenas nos casos de falta grave, mas também por insuficiência de desempenho ou por excesso de despesa com pessoal. Tais princípios foram aprovados com a Emenda Constitucional no 19, de maio de 1998, mas sua regulamentação não foi até hoje concluída. ${ }^{24}$

O principal obstáculo à regulamentação deste novo dispositivo constitucional é a definição de quais sejam as carreiras típicas de Estado — que terão maior proteção diante da demissão. O projeto de lei foi encaminhado pelo Executivo ao Congresso no final de 1998, mas não foi ainda apreciado, por falta de consenso, inclusive entre a base parlamentar de apoio ao governo. Segundo o ex-Ministro Bresser Pereira, a proposta que acabou sendo enviada pelo Executivo foi equivocada, tendo sido excessivamente 
restritiva - abrangia apenas os diplomatas e os advogados da União; isto poderia ter contribuído para ampliar o lobby de vários setores da administração pública que, por meio de emendas de parlamentares, estendem indefinidamente a lista de carreiras típicas de Estado.

Também não foi concluída a votação do projeto de lei que disciplina a perda de cargo, do servidor estável, por avaliação periódica de desempenho. Em 1998, o Executivo encaminhou ao Congresso projeto de lei complementar (PLC 248/98), até hoje não apreciado pelos parlamentares. Da qualidade desta regulamentação depende que o novo dispositivo não seja transformado em mais uma peça burocrática e retórica, de quase impossível aplicação.

A Emenda Constitucional também abriu a possibilidade de que os servidores sejam contratados por mais do que um único regime jurídico, tendo sido recriado o "emprego público" como vínculo empregatício. ${ }^{25}$ Ainda aqui, há riscos de excessiva burocratização na aplicação dos dispositivos, transformando o empregado público na prática em servidor inamovível; pela lei aprovada, a principal diferença entre o regime de emprego público e o regime estatutário é o sistema de aposentadorias, que no primeiro caso será regido pelo Regime Geral da Previdência. Ainda assim, o regime de emprego público não pôde ser aplicado até hoje, pois foi questionado junto ao Supremo Tribunal Federal.

\section{Limites legais à despesa de pessoal}

Uma série de legislações vem dispondo sobre limites às despesas de pessoal. A primeira delas, conhecida como Lei Camata, de 1995, determinou que esta porcentagem não pode exceder a $60 \%$ da receita corrente líquida de cada esfera de governo, concedendo um prazo de três anos para que as três esferas de governo se ajustassem ao limite.

Posteriormente, para a esfera federal, este limite foi reduzido para 50\%, pela Lei Complementar no 96, de 31 de maio de 1999. A Emenda Constitucional no 19, de 1998, deu novo prazo a Estados e municípios para adequarem seus gastos com pessoal aos limites estabelecidos.

A Lei de Responsabilidade Fiscal (LRF), de 04 de maio de 2000, diferenciou este limite entre os poderes dentro de cada esfera de governo. Para a União, estabeleceu que os gastos totais com pessoal não podem ultrapassar 40,9\% da receita Corrente Líquida para o Executivo, 6\% para o Judiciário, 2,5\% para o Legislativo, incluído o Tribunal de Contas da União, e 0,6\% para o Ministério Público da União.

O maior impacto destes limites fixados tem incidido sobre os gastos de pessoal nos governos estaduais e municipais. Em 1995, a grande maioria dos Estados tinha seus gastos com pessoal acima dos limites fixados: Espírito 
Santo, por exemplo, gastava $91 \%$ de sua receita líquida com pessoal; Santa Catarina, 90\%; São Paulo, 85\%. Em 2001, dados relativos a 20 Estados apontaram que apenas dois Estados (Rio Grande do Sul e Minas Gerais) se encontravam acima do limite de 60\% (BNDES-AFE, 2002a). ${ }^{26}$

A LRF tem papel importante no controle das despesas com pessoal, ao fixar percentuais para cada poder, dentro de cada esfera de governo. Dada a autonomia de poderes, antes da LRF era muito difícil fazer com que a redução de despesas com pessoal não recaísse apenas sobre o Executivo - cuja margem de ação fica restrita aos servidores ativos.

\section{A agenda positiva: novos ingressos por concurso e capacitação permanente}

Uma ação decisiva para obter os resultados alcançados, no período 1995-2002, foi a política praticada de concursos públicos anuais para determinadas carreiras cujas atividades são essenciais, além da criação de algumas novas carreiras. Desde 1995, o Ministério da Administração Federal e Reforma do Estado (MARE) adotou a programação anual de concursos públicos, considerando um horizonte de cinco anos. ${ }^{27}$

Tal medida tinha por objetivo promover ingressos regulares e sistemáticos no setor público, tendo como parâmetro geral, para a definição do número de vagas por concurso, a reposição de 1/30 do total de cargos de cada carreira a cada ano - considerando ser este, aproximadamente, o ciclo de reposição de servidores. Por outro lado, a previsibilidade de cinco anos permitiria aos candidatos um melhor planejamento de seu ingresso no setor público, e servia de argumento às pressões de determinados órgãos pela criação imediata de grande número de vagas.

Historicamente, os concursos de ingresso no setor público foram irregulares — alternavam-se períodos de "grandes concursos" (com muitas vagas, de uma só vez), seguidos de longos períodos sem contratação; isto tendeu a provocar gaps entre gerações, dificultando até mesmo a continuidade de políticas públicas.

Outra prática tradicional, também modificada a partir de 1995, era a de aprovar um grande número de candidatos em cada concurso, e só convocar para a posse uma parcela dentre os aprovados; os demais ficavam em uma "lista de espera", podendo vir a ser convocados até quatro ou mais anos depois. A consequiência acabava sendo a de admitir pessoas que já não tinham o mesmo interesse de ingressar no setor público, assim o fazendo muito mais por conveniência do que por opção profissional.

Com a nova política de concursos, passou-se a aprovar os candidatos correspondentes ao estrito número de vagas em cada concurso; os demais deveriam reafirmar sua opção no ano subseqüente, preparando-se e submetendo-se a um novo concurso. 
Por meio desta política, ingressaram no serviço público federal, entre 1995 e 2001, 51.583 novos servidores, o que representa mais de $12 \%$ do total dos servidores ativos federais em 2001. Isto significa uma alta taxa de renovação da força de trabalho.

Se considerarmos o perfil dos cargos, a constatação é a de que esta renovação foi condizente com a alteração do perfil da força de trabalho que se queria alcançar, já que a política privilegiou o ingresso para cargos de nível superior. Do total de mais de 51 mil ingressantes, 59\% passaram a ocupar cargos de nível superior. Excluindo os ingressos realizados em 1995, cujos concursos podem ter sido autorizados no governo anterior, temos que $71 \%$ dos cargos preenchidos foram de nível superior. Os dados são apresentados na Tabela 12.

\section{Tabela 12: Ingressos por concurso público no serviço} público federal, por nível de escolaridade

\begin{tabular}{l|r|r|r|r|r|r|r|r|r}
\hline Nível do cargo & 1995 & 1996 & 1997 & 1998 & 1999 & 2000 & 2001 & \multicolumn{2}{|c}{ Total } \\
\hline & & & & & & & & n.a. & $\%$ \\
\hline Superior & 7.709 & 6.309 & 6.574 & 5.861 & 1.937 & 1.348 & 621 & 30.359 & 58,9 \\
\hline Intermediário & 10.097 & 3.251 & 2.387 & 1.879 & 988 & 176 & 39 & 18.817 & 36,5 \\
\hline Auxiliar & 1.869 & 367 & 94 & 75 & 2 & 0 & 0 & 2.407 & 4,6 \\
\hline Total & 19.675 & 9.927 & 9.055 & 7.815 & 2.927 & 1.524 & 640 & 51.583 & 100,0 \\
\hline
\end{tabular}

Fonte: MP — Boletim Estatístico de Pessoal no 77, agosto/2002.

\section{Tabela 13: Ingressos por contratação por tempo} determinado, por nível de escolaridade

(1995 a setembro/2001)

\begin{tabular}{l|r|r|r|r|r|r|r|r|r}
\hline Nível do cargo & 1995 & 1996 & 1997 & 1998 & 1999 & 2000 & $2001^{1}$ & \multicolumn{2}{|c}{ Total } \\
\hline & & & & & & & & n.a. & $\%$ \\
\hline Superior & 5.351 & 7.687 & 7.248 & 5.821 & 5.056 & 7.045 & 5.965 & 44.173 & 76,4 \\
\hline Intermediário & 1 & 118 & 1.416 & 1.508 & 932 & 2.109 & 2.464 & 8.548 & 14,8 \\
\hline Auxiliar & 9 & 102 & 0 & 3 & 0 & 0 & 0 & 114 & 0,2 \\
\hline Outro $^{2}$ & 107 & 866 & 844 & 345 & 637 & 611 & 1.564 & 4.974 & 8,6 \\
\hline Total & 5.468 & 8.773 & 9.508 & 7.677 & 6.625 & 9.765 & 9.993 & 57.809 & 100,0 \\
\hline
\end{tabular}

Fonte: MP — Boletim Estatístico de Pessoal no 66, outubro/2001.

${ }^{1}$ Posição: setembro/2001.

${ }^{2}$ Recenseador do IBGE.

Além dos servidores permanentes ingressados por concurso, outros 57.809 ingressaram por contratação por tempo determinado (também por meio de concurso público), 76,4\% dos quais para cargos de nível superior. 
Os ingressos por concurso público tiveram uma desaceleração a partir de 1999, por conta do enfrentamento da grave crise fiscal naquele ano. Os ingressos por tempo determinado também foram reduzidos em 1999, tendo em seguida retomado seu volume anterior. De toda a forma, a política de ingressos será melhor delineada depois de equacionada a questão da previdência do setor público, e quando for concluída a regulamentação da emenda constitucional da administração pública, que admitiu um novo regime de contratação — o emprego público.

A capacitação permanente dos servidores foi intensificada a partir de 1995: só na ENAP foram treinados mais de 132 mil servidores, entre 1995 e 2002; em 14 anos anteriores, entre 1981 e 1994, haviam sido treinados cerca de 42 mil servidores. A Escola de Administração Fazendária (ESAF), vinculada ao Ministério da Fazenda, também realizou expressiva quantidade de treinamentos, além de outras instituições públicas e privadas contratadas pelos diversos órgãos federais.

$\mathrm{O}$ aumento do número de treinamentos foi em parte possibilitado por uma nova visão acerca do papel da capacitação no setor público: tradicionalmente, a capacitação era vista como um requisito para promoção na carreira; com a agenda de reforma pós-95, a capacitação passou a ser considerada tanto de interesse do servidor como de sua instituição. Esta nova visão permitiu quebrar o imobilismo anterior, em que as pressões corporativas buscavam antes a criação de novas carreiras estruturadas do que a capacitação como atualização permanente.

Outro mito desfeito foi o que tendia a dar valor apenas aos longos programas de formação, em detrimento dos cursos curtos de atualização. A preferência por cursos de formação, inclusive especializações e mestrados, tinha por base uma falta de clareza do âmbito e especificidade da capacitação profissional — voltada ao trabalho, à solução de problemas; a visão anterior era mais acadêmica, tendendo a não diferenciar os conteúdos e métodos da formação universitária e da capacitação profissional.

Estas visões foram consolidadas no decreto que instituiu a Política Nacional de Capacitação, em 1998. O decreto introduziu a noção de públicos-alvo prioritários a serem capacitados, temas prioritários, e ainda uma visão gerencial da capacitação, propondo tornar públicos os dados comparativos entre as diversas instituições federais, sobre o gasto com capacitação e o atendimento dos públicos-alvo prioritários.

Infelizmente, a implementação do decreto foi burocratizada, e ainda não alcançou os resultados visados. Não há hoje informações gerenciais sobre a capacitação de servidores públicos federais. Temos a hipótese de que hoje se gasta muito com capacitação — o problema não é necessariamente de falta de recursos, mas gasta-se mal - sem mensurar os resultados, e até mesmo sem clareza sobre as prioridades e as especificidades 
do setor público. As instituições precisam aprimorar sua competência como "compradores" de capacitação, não se deixando levar por modas ou grifes de fornecedores.

Por outro lado, a distribuição de recursos para a capacitação, entre os diversos órgãos federais, é ainda muito desigual. A Política Nacional de Capacitação lidou com esse problema como um dado da realidade, impossível de ser alterado a curtíssimo prazo ou por força de decreto; apostou que, com a publicização de dados comparativos, se poderia caminhar, em alguns anos, para um per capita a ser definido para a capacitação.

A maior efetividade no uso de recursos destinados à capacitação depende também de um realinhamento estratégico das áreas de recursos humanos das instituições federais. As coordenações de RRHH precisam rever sua postura tradicional, que tendeu a considerar como seu objetivo principal "assegurar o bem-estar dos servidores". Esta postura não ajuda a que o tema recursos humanos seja incluído na agenda dos dirigentes, e nem cria condições favoráveis para as mudanças que se quer produzir no setor público. Se as áreas de RRHH se posicionarem como agentes de mudança — e não "defensores do status quo", e entenderem como objetivo maior o de apoiar o desenvolvimento de pessoas para que a instituição alcance seus resultados, a capacitação poderá tomar novo impulso e maior eficácia.

\section{Balanço e perspectivas}

O presente texto abordou vários aspectos da gestão de recursos humanos na administração federal, desde 1995. A evolução recente dos efetivos na função pública federal brasileira não resulta apenas de medidas adotadas, mas também de processos mais subjetivos — apreensão com os rumos da reforma, ou particularistas — cálculos individuais de lucros e perdas com a permanência ou a saída da função pública.

Assim, para o novo perfil da força de trabalho que está se delineando, tanto contribuíram as precoces e vantajosas aposentadorias dos "apreensivos", como a política de concursos anuais direcionados para cargos de nível superior. Mais relevante do que as causas parece ter sido os resultados - de que a força de trabalho vai assumindo um perfil compatível com os desafios à função pública impostos pelos novos papéis do Estado, e consistente com as propostas para a reforma do aparelho do Estado.

Nenhuma eficácia teria uma política de recursos humanos que quisesse se antepor aos desafios da estabilização econômica e do ajuste fiscal. A inteligência das medidas adotadas reside exatamente em não aceitar esta aparente oposição, e sim buscar conciliar as restrições fiscais com a condução da mudança do perfil e da qualificação dos recursos humanos. Afinal, conhecer e compreender os dados da realidade e trabalhar 
a partir deles é competência fundamental de qualquer formulador de políticas públicas, inclusive daqueles responsáveis pelas políticas de gestão e de recursos humanos.

Arriscaríamos afirmar que, pela ordem, um conjunto de atores importantes precisam ser sensibilizados para fazer avançar as mudanças em curso, quanto à função pública: a opinião pública, os formadores de opinião, a classe política/os parlamentares, e finalmente os pesquisadores e comunidade acadêmica dedicados aos temas do Estado e da administração pública. Consideramos que estes atores apresentam hoje uma gradação, indo da opinião mais favorável às mudanças pelo primeiro segmento - a opinião pública, até às maiores incompreensões e resistências dos dois últimos grupos - políticos e pesquisadores.

Ao governo, e aos responsáveis pelas políticas de gestão, dentre os quais me incluo, faltou maior assertividade - consolidar, dar lógica às mudanças em curso, interpretar, "dar o sentido" em suas duas acepções (sentido como direção a seguir, e sentido como significado) — demos a direção, mas não o significado das mudanças. Ao explicar o sentido das mudanças, resistir às pequenas pressões, às vezes internas ao governo, por medidas pontuais que se afastam da orientação geral - como por exemplo a criação de carreiras onde não é necessário, a extensão de benefícios a cargos de nível médio, a abertura de concursos não condizentes com as diretrizes estabelecidas.

Este tema - a força de trabalho do setor público — como vários outros objetos das políticas públicas e das reformas em curso no Brasil traz à tona questões profundas como a natureza do federalismo brasileiro, a relação entre poderes, as desigualdades regionais, as injustiças sociais e os privilégios, a bandeira fácil da isonomia - que por trás da aparência de "tratamento igual a todos" esconde a falta de coragem para avaliar e recompensar os desempenhos diferentes; as dificuldades em entender e aceitar o sentido profundo da meritrocacia etc.

Talvez este emaranhado de temas e dilemas dê ainda mais sentido ao que o Presidente Fernando Henrique, em seu balanço de sete anos de governo, referindo-se à gestão de recursos humanos, chamou de "administrar o passivo":

"A revisão dos conceitos de gestão de recursos humanos deve ser feita em sintonia com os princípios da responsabilidade fiscal e do equilíbrio das contas públicas. É preciso inovar e, simultaneamente, administrar o passivo existente nessa área, de forma a fazêlo convergir para a mudança. As mudanças realizadas nos últimos sete anos pautaram-se por esses princípios." ${ }^{28}$ 
Texto inicialmente apresentado ao 3o Encontro do INA, realizado em Lisboa, 14 e 15 de março de 2002, com o título "O controle do aumento de efetivos na função pública brasileira". Atualizado para publicação na Revista do Serviço Público.

2 Mensagem presidencial à abertura do ano legislativo de 2002, 15 de fevereiro de 2002.

3 "Num período de 10 anos, só a privatização de empresas estatais federais arrecadou quase U\$ 70 bilhões, incluindo receita de venda e dívidas transferidas. Mais de 80 empresas saíram do controle do Governo Central.” (Martus Tavares, Ministro do Planejamento, Orçamento e Gestão, palestra em seminário da OCDE, 11 de fevereiro de 2002).

${ }^{4}$ MARE, 1995 - Plano Diretor da Reforma do Aparelho do Estado. Grifos meus.

5 Presidência da República, Mensagem ao Congresso Nacional, 15 de fevereiro de 2002, p.503.

6 MARE, 1995, idem.

7 A diferença entre os cargos e a escolaridade dos servidores decorre de disposição constitucional, desde 1988, que impede a ascensão funcional de servidores; assim, mesmo que um servidor ocupante de um cargo de nível médio tenha concluído seus estudos superiores, não poderá passar para um cargo de nível superior, a menos que seja aprovado em concurso público nacional, aberto a qualquer cidadão. Por outro lado, vários concursos para cargo de nível médio são disputados por pessoas que já concluíram estudos universitários, e que optam pela estabilidade do emprego público e pelas vantagens da aposentadoria integral, exclusiva do setor público.

8 Muitos servidores deixam de atualizar seus dados cadastrais, especialmente quanto à escolaridade, em parte devido ao dispositivo constitucional que vedou, a partir de 1988, a possibilidade de ascensão interna.

9 Luiz Carlos Bresser Pereira, mentor da reforma de 1995 e Ministro da Administração Federal e Reforma do Estado durante o primeiro governo Fernando Henrique Cardoso (1995-1998).

${ }^{10}$ Ver artigo da jornalista Marluza Mattos, publicado no jornal Valor Econômico, em 28 de janeiro de 2002.

${ }^{11}$ O primeiro Programa de Demissão Voluntária (PDV) foi anunciado em 1996, e teve a adesão de 7.800 servidores; o segundo PDV foi realizado em 1999, com 5.733 adesões; no ano de 2000, o terceiro PDV obteve o desligamento voluntário de 1.418 servidores; neste programa, houve cláusula de barreira para algumas carreiras — advogados, procuradores, diplomatas, delegados e agentes da polícia federal, e auditores fiscais. O segundo programa abriu ainda duas outras opções permanentes aos servidores: redução de jornada de trabalho com redução proporcional de remuneração, e incentivo à licença sem remuneração.

${ }^{12} \mathrm{O}$ quantitativo de militares ativos se mantém estável em torno de 330 mil, entre 1991 e 2000, com uma única retração importante em 1998 (277 mil).

${ }^{13}$ BNDES-AFE (2002).

${ }^{14}$ Fonte: RAIS 2000 preliminar — segundo BNDES-AFE (2002). Os dados são apresentados no Anexo 1.

${ }^{15}$ Durante o governo Collor (1990-92), houve uma queda generalizada dos níveis reais de salário no setor público; a partir de 1993, o governo Itamar buscou recuperar os níveis salariais dos servidores, por meio de aumentos lineares, recompondo o nível salarial dos anos 80 . 
${ }^{16}$ Presidência da República, Mensagem ao Congresso Nacional, 15 de fevereiro de 2002, p. 511.

${ }^{17}$ Idem, p.511.

${ }^{18}$ Dados de setembro/2002: o PCC abrangia 233.272 servidores; apenas 20,3\% dos cargos do PCC são de nível superior.

${ }^{19}$ FCT instituída pela Medida Provisória no 2048-26, de 29 de junho de 2000.

${ }^{20}$ Lei no 10.404 , de 09 de janeiro de 2002 — cria a Gratificação de Desempenho de Atividade Técnico-Administrativa (GDATA).

${ }^{21}$ Nos dois casos, homens e mulheres, a exigência de idade mínima para trabalhadores do setor privado é de 5 anos a mais.

${ }^{22}$ MARE, 1995 - Plano Diretor da reforma do Aparelho do Estado.

${ }^{23}$ Poucos dados existem a respeito - ver Anexo 2.

${ }^{24}$ A demissão por excesso de despesa foi regulamentada pela lei no 9.801 , de 16 de junho de 1999, valendo para as três esferas de governo e para os três poderes; no entanto, no caso da União, sua implementação depende da definição de quais sejam as carreiras típicas de Estado. Ainda no caso da União, o limite para gasto com pessoal, fixado em $50 \%$ da Receita Corrente Líquida da União, não foi ultrapassado.

${ }^{25} \mathrm{O}$ regime de emprego público foi regulamentado pela lei no 9.962, de fevereiro de 2000 .

${ }^{26}$ Os dados disponíveis encontram-se no Anexo 3.

${ }^{27}$ Ver Portarias no 1.731 e 1.732 , de julho/1997 e alterações posteriores

${ }^{28}$ Presidência da República, Mensagem ao Congresso Nacional, 15 de fevereiro de 2002, p.512. 
Anexo 1

Participação da administração pública no emprego formal (em \%)

\begin{tabular}{|c|c|}
\hline Estado da federação & $\%$ do emprego público no emprego formal \\
\hline Acre & 58,5 \\
\hline Amapá & 30,1 \\
\hline Amazonas & 33,1 \\
\hline Pará & 28,5 \\
\hline Rondônia & 42,5 \\
\hline Roraima & 51,5 \\
\hline Tocantins & 47,6 \\
\hline Região Norte & 35,6 \\
\hline Alagoas & 34,7 \\
\hline Bahia & 33,6 \\
\hline Ceará & 29,9 \\
\hline Maranhão & 44,5 \\
\hline Paraíba & 46,7 \\
\hline Pernambuco & 32,7 \\
\hline Piauí & 35,0 \\
\hline Rio Grande do Norte & 40,3 \\
\hline Sergipe & 40,5 \\
\hline Região Nordeste & 35,5 \\
\hline Distrito Federal & 50,3 \\
\hline Goiás & 25,7 \\
\hline Mato Grosso & 23,4 \\
\hline Mato Grosso do Sul & 25,6 \\
\hline Região Centro-Oeste & 34,9 \\
\hline Espírito Santo & 23,4 \\
\hline Minas Gerais & 16,3 \\
\hline Rio de Janeiro & 21,4 \\
\hline São Paulo & 17,1 \\
\hline Região Sudeste & 18,0 \\
\hline Paraná & 20,5 \\
\hline Rio Grande do Sul & 20,4 \\
\hline Santa Catarina & 15,8 \\
\hline Região Sul & 19,3 \\
\hline Total - Brasil & 23,2 \\
\hline
\end{tabular}

Fonte: RAIS 2000, cf. BNDES-AFE (2002). 
Anexo 2

Processos de desligamento dos servidores estatutários civis do Poder Executivo

\begin{tabular}{l|c|c|c|c|c}
\hline \multirow{2}{*}{ Ano } & \multirow{2}{*}{$\begin{array}{l}\text { Universo } \\
\text { considerado }\end{array}$} & \multicolumn{2}{|l|}{ Demissões } & Reintegrações & \multirow{2}{*}{$\begin{array}{l}\text { Processos } \\
\text { nulos }\end{array}$} \\
\cline { 3 - 4 } & n.a. & $\%$ & 4 & 74 \\
\hline 1993 & 592.898 & 253 & 0,043 & 20 & 24 \\
\hline 1994 & 583.020 & 376 & 0,064 & 5 & 12 \\
\hline $1995 *$ & 576.930 & 20 & 0,003 & & 4 \\
\hline
\end{tabular}

Fonte: MARE - Boletim Estatístico de Pessoal BEP no 15, julho/1997, p.45.

* Até julho. 
Anexo 3

Relação entre gastos com pessoal e receita líquida em Estados da Federação

\begin{tabular}{|c|c|c|c|c|}
\hline \multirow[t]{2}{*}{ Estado } & \multicolumn{4}{|c|}{$\%$ gasto sobre receita líquida } \\
\hline & Julho/1995 ${ }^{1}$ & $1997^{2}$ & $1998^{3}$ & $2001^{3}$ \\
\hline Espírito Santo & 91 & 80 & 89,6 & 49,6 \\
\hline Santa Catarina & 90 & 62,93 & 89,3 & 55,4 \\
\hline Alagoas & 88 & 65,61 & n.d. & n.d. \\
\hline Piauí & 85 & 78,5 & 66,8 & 58,6 \\
\hline São Paulo & 85 & 61,1 & 63,7 & 55,1 \\
\hline Rio Grande do Norte & 82 & n.d. & n.d. & n.d. \\
\hline Rio Grande do Sul & 81 & 86,5 & n.d. & 71,3 \\
\hline Distrito Federal & 81 & 82 & 70,7 & 35,3 \\
\hline Goiás & 80 & 72,56 & 73,4 & 57,7 \\
\hline Pernambuco & 78 & 77,1 & 70,8 & 57,0 \\
\hline Paraná & 77 & n.d. & 66,8 & 56,8 \\
\hline Minas Gerais & 72 & 67,36 & 73,1 & 70,0 \\
\hline Paraíba & 70 & 69 & n.d. & n.d. \\
\hline Rio de Janeiro & 70 & 85 & n.d. & 45,9 \\
\hline Ceará & 66 & 64,26 & 56,7 & 50,2 \\
\hline Bahia & 65 & 54,09 & 52,5 & 46,7 \\
\hline Amapá & n.d. & 57 & n.d. & n.d. \\
\hline Rondônia & n.d. & 71,6 & n.d. & n.d. \\
\hline Sergipe & n.d. & 66,69 & n.d. & 55,0 \\
\hline Mato Grosso do Sul & n.d. & 64,69 & 56,1 & 53,6 \\
\hline Maranhão & n.d. & 53,59 & n.d. & 53,8 \\
\hline Tocantins & n.d. & 49,42 & n.d. & 37,6 \\
\hline Roraima & n.d. & 30,04 & 40,8 & 42,4 \\
\hline Mato Grosso & n.d. & n.d. & 59,4 & 55,0 \\
\hline Amazonas & n.d. & n.d. & n.d. & 45,4 \\
\hline Média & 78,6 & n.d. & n.d. & n.d. \\
\hline
\end{tabular}

Fonte: (1)BEP nº 1, maio/1996; (2) Abrucio e Costa (1998); (3) BNDES-AFE (2002a). 


\section{Referências bibliográficas}

Abrucio, Fernando; Valeriano M. F. Costa. (1998), "Reforma do Estado e o contexto federativo brasileiro". Série Pesquisas no 12, São Paulo: Fundação Konrad Adenauer.

BNDES-Afe, Área de Assuntos Fiscais. (2002), "Emprego: participação dos empregos do setor público no mercado de trabalho". Informe-se, no 42 .

. (2002a), "Responsabilidade Fiscal: o comportamento das despesas estaduais com pessoal após a Lei de Responsabilidade Fiscal”. Informe-se no 44.

Brasil. (1995), Plano Diretor da Reforma do Aparelho do Estado. Brasília: Presidência da República.

MarConi, Nelson. (2001), “A formação do salário nos setores público e privado”. Tese de doutorado apresentada à EAESP-FGV. São Paulo, mimeo.

Ministério da AdministraÇão Federal e Reforma do Estado. (1996 a 1998), BEP — Boletim Estatístico de Pessoal. Publicação mensal; vários números. Disponíveis no site www.servidor.gov.br — ver Publicações.

Ministério do Planejamento, OrÇamento e Gestão. (1999 a 2002), BEP — Boletim Estatístico de Pessoal. Publicação mensal; vários números. Disponíveis no site www.servidor.gov.br — ver Publicações.

PAcheCo, Regina Silvia. (2002), "O controle do aumento de efetivos na função pública brasileira”. In INA-Instituto Nacional de Administração, A Reinvenção da Função Pública. Lisboa, INA, pp.49-68.

PresidênCIA dA RePÚBlica. (2002), Mensagem ao Congresso Nacional, 15 de fevereiro. 
Revista do

Serviço

Público

Ano 53

Número 4

Out-Dez 2002

Regina Silvia

Pacheco é

presidente da

ENAP Brasil

Escola Nacional

de Administra-

ção pública

desde março de

1995.

Professora

doutora da

EAESP-FGV -

São Paulo,

licenciada.

Contato:

regina.pacheco@ enap.gov.br

\section{Política de recursos humanos para a reforma gerencial: realizações do período 1995-2002 \\ Regina Silvia Pacheco}

O texto apresenta as principais ações realizadas pelo Governo Federal no período 1995-2002, na área de recursos humanos. Busca relacionar tal evolução com a agenda de reforma do aparelho de Estado, em implantação no país. Em especial, discute a evolução do perfil da força de trabalho na Administração Pública Federal, em direção a um perfil mais condizente com os novos papéis do Estado na esfera federal. As ações empreendidas mostram coerência com os objetivos fixados no Plano Diretor de Reforma do Aparelho do Estado, que visavam: "Modernizar a administração burocrática, através de uma política de profissionalização do serviço público, ou seja, de uma política de carreiras, de concursos públicos anuais, de programas de educação continuada permanente, de uma efetiva administração salarial, ao mesmo tempo em que se introduz no sistema burocrático uma cultura gerencial baseada na avaliação de desempenho".

Em 1995, menos de 40\% dos servidores federais tinham escolaridade de nível superior. Em 2001, pela primeira vez, os servidores de nível superior passaram a constituir mais da metade da força de trabalho. Os dados indicam uma verdadeira revolução no perfil da força de trabalho no setor público federal - ainda pouco conhecida.

A política de recursos humanos buscou conciliar a mudança desejada do perfil e da qualificação dos recursos humanos às restrições fiscais. Novos conceitos sobre profissionalização permitiram que a capacitação permanente dos servidores fosse intensificada. O Governo Federal praticou uma nova política remuneratória, por meio de reajustes diferenciados, buscando diminuir as distorções existentes em comparação ao setor privado, reter seus quadros mais qualificados e atrair novos servidores para as carreiras de Estado para as quais foram organizados concursos anuais de ingresso.

Em dois campos os avanços foram apenas parciais: na reforma do sistema de aposentadorias do setor público, na revisão do estatuto da flexibilidade (demissão não apenas nos casos de falta grave, mas também por insuficiência de desempenho ou por excesso de despesa com pessoal). Ainda assim, os dados mostram que a evolução recente dos efetivos não resulta apenas de medidas adotadas, mas também de processos mais subjetivos - a apreensão com os rumos da reforma levou a uma "corrida à aposentadoria", como acontece, aliás, a cada vez que se retoma o debate em torno da alteração das regras.

Este tema - a força de trabalho do setor público - como vários outros objetos das políticas públicas e das reformas em curso no Brasil - traz à tona questões profundas, como a natureza do federalismo brasileiro, a relação entre poderes, as desigualdades regionais, as injustiças sociais e os privilégios, a bandeira fácil da isonomia.

\section{Política de recursos humanos para la reforma gerencial: realizaciones del periodo 1995-2002}

Regina Silvia Pacheco

El texto presenta las principales acciones realizadas por el Gobierno Federal en el período 1995-2002, en el área de recursos humanos. Busca relacionar tal evolución con la agenda de reforma del aparato de Estado, en implantación en el país. En especial, discute la evolución del perfil de la fuerza de trabajo en la administración pública federal, en dirección a un perfil más harmonioso con los nuevos papeles del Estado en la esfera federal. Las acciones iniciadas han mostrado coherencia con los objetivos establecidos en el Plan Director 
de Reforma del Aparato del Estado, que objetivaban: "Modernizar la administración burocrática, a través de una política de profesionalización del servicio público, o sea, de una política de carreras, de concursos públicos anuales, de programas de educación seguida permanente, de una efectiva administración salarial, al paso en que se introduce en el sistema burocrático una cultura gerencial basada en la evaluación de desempeño".

En 1995, menos del 40\% de los servidores federales tenían escolaridad de nivel superior. En 2001, por la primera vez, los servidores de nivel superior pasaron a constituir más de la mitad de la fuerza de trabajo. Los datos indican una verdadera revolución en el perfil de la fuerza de trabajo en el sector público federal — hace poco conocida.

La política de recursos humanos buscó conciliar el cambio deseado del perfil y de la calificación de los recursos humanos a las restricciones fiscales. Nuevos conceptos sobre profesionalización han permitido que la capacitación permanente de los servidores fuese intensificada. El Gobierno Federal practicó una nueva política remuneratoria, por medio de reajustes diferenciados, buscando disminuir las distorsiones existentes en comparación con el sector privado, retener sus cuadros más calificados y atraer nuevos servidores para las carreras de Estado - para las cuales han sido organizados concursos anuales de ingreso.

En dos campos los avances han sido apenas parciales: en la reforma del sistema de jubilaciones del sector público, en la revisión del estatuto de la flexibilidad (demisión no apenas en los casos de falta grave, pero también por insuficiencia de desempeño o por exceso de gasto con personal). Mismo así, los datos muestran que la evolución reciente de los efectivos no resulta apenas de medidas adoptadas, pero también de procesos más subjetivos - la aprensión con los rumbos de la reforma lo condujo a una "corrida a la jubilación”, como acontece, además, a cada vez que se retoma el debate en torno de la alteración de las reglas.

Este tema - la fuerza de trabajo del sector público — como varios otros objetos de las políticas públicas y de las reformas en curso en Brasil — trae a la luz cuestiones profundas como la naturaleza del federalismo brasileño, la relación entre poderes, las desigualdades regionales, las injusticias sociales y los privilegios, la bandera fácil de la isonomia.

\section{Human resources policy for the managerial renovation: accomplishments between 1995-2002 \\ Regina Silvia Pacheco}

The text presents the main actions carried out by the Federal Government between 1995-2002 in the field of human resources. Its intention is to correlate this evolution with the State organization renovation agenda being implemented in the country. Specially, it discusses the evolution of the workforce profile in the public federal administration to a much more suitable profile for the new roles of the State in the federal scope. The actions undertaken demonstrate coherence with the objectives set forth in the Directive Plan of the State Organization Renovation, which aimed at: "Modernizing the bureaucratic administration by professionalizing the governmental staff, that is, by carrier plan policies, annual admittance examinations, continuing education programs, and an effective salary administration, at the same time that a managerial culture is introduced to the bureaucratic system, based on performance evaluations".

In 1995, less than $40 \%$ of the federal employees had a college-level education. In 2001, for the first time, employees with college-level education became more than half of the work force. The data indicate an actual revolution in the profile of the public federal sector work force - which is still not very known.

The policy of human resources attempted to conciliate the desired changes in the profile and qualification of the human resources with tax restrictions. New concepts of professionalization allowed the permanent capacitation of employees to be intensified. The Federal Government practiced a compensation policy through differentiated readjusts, in order to reduce the distortions compared to the private sector, retain its better qualified staff, and attract new employees to State carriers - for which annual admittance examinations were prepared. 
Two sectors had only partial advancements: the renovation of the public sector retirement system, and the revision of the flexibility statute (dismissal not only in cases of severe fault, but also for performance insufficiency or excessive personnel expenses). Notwithstanding, the data show that the recent staffing evolution is not a consequence of the adopted measures only, but also of more subjective processes — the apprehension with the renovation course led to a "retirement rush", as it happens every time a debate is held about changing the rules.

This issue - the public sector work force — as many other objects of ongoing public policies and renovations in Brazil - brings deeper issues, such as the nature of Brazilian federalism, the relation between powers, regional inequalities, social injustices, and privileges, to the easy rank of isonomy. 